CLINICAL STUDY

\title{
Locoregional recurrence and death from medullary thyroid carcinoma in a contemporaneous series: 5 -year results
}

\author{
Andreas Machens ${ }^{1}$, Christine Hofmann ${ }^{1}$, Steffen Hauptmann ${ }^{2}$ and Henning Dralle ${ }^{1}$ \\ Departments of ${ }^{1}$ General, Visceral and Vascular Surgery and ${ }^{2}$ Pathology, Martin-Luther-University Halle-Wittenberg, Ernst-Grube-Straße 40, D-06097 \\ Halle/Saale, Germany \\ (Correspondence should be addressed to A Machens; Email: andreasmachens@aol.com)
}

A Machens and C Hofmann contributed equally to this work

\begin{abstract}
Objective: Studies of outcome in patients with medullary thyroid carcinoma require long follow-ups to accrue enough cancer-specific events. Owing to time-dependent changes in diagnosis and therapy, long observation periods render studies susceptible to 'time bias' which can yield spurious results. This study was designed to investigate cancer-specific event rates after initial neck resection in contemporaneous patients recruited within less than a decade.

Design: Institutional cohort study of 128 consecutive patients who underwent compartment-oriented neck surgery between 1994 and 2002 at a tertiary surgical center for hitherto untreated medullary thyroid carcinoma.

Methods: The Kaplan-Meier method was used in conjunction with the log-rank test for analysis of time-dependent outcomes.

Results: Follow-up was available for 120 patients (94\%) including 63 rearranged during transfection (RET) carriers. There were six locoregional recurrences in the 110 patients with clear surgical margins at initial neck resection, and 12 cancer-specific deaths in the 120 patients with available follow-up. On Kaplan-Meier analysis, most clinicopathological variables were significantly associated with recurrence-free survival and cancer-specific survival. Within the median observation period of 64.5 months, patients with node-negative tumors did not develop locoregional recurrence or die from their malignancies. The low event rates precluded multivariate analyses with all clinicopathological variables. With our extensive surgical approach, median recurrence-free survival and cancer-specific survival at 5 years were 95.2 and $89.3 \%$ respectively.

Discussion: Compared with literature data, our 5-year locoregional recurrence rate of $4.8 \%$ appeared very favorable, and our 5-year cancer-specific mortality rate of $10.7 \%$ was among the lowest ever reported. The growing proportion of localized medullary thyroid carcinomas among contemporaneous patients can be expected to ultimately lower the event rates, complicating future studies of outcome.
\end{abstract}

European Journal of Endocrinology 157 85-93

\section{Introduction}

With an age-standardized incidence of 0.18 in men and 0.23 in women per 100000 inhabitants (1), medullary thyroid carcinoma, a C-cell-derived parafollicular neoplasm of neural crest origin, is considered a rare disease. The infrequency of the condition, which occurs in a sporadic and a hereditary variant, can render the design and conduct of studies of outcome challenging, often enforcing a complex large-scale multicenter setup. Because of the low event rates (locoregional recurrence and cancer-specific death) in patients with medullary thyroid carcinoma, long periods of follow-up are needed to accrue sufficient numbers of events, allowing for multivariate analyses of interrelated factors. Long observation periods, however, can lead to loss of patients who may have moved from the area or may have died from the tumor or from causes unrelated to the condition of interest. Vanishing study participants can introduce bias into the study when, for instance, sicker patients with more advanced disease are preferentially lost to follow-up.

National population-based registries, such as the Surveillance, Epidemiology, and End Results (SEER) Program database in the US, may lend themselves as remedies to some of the challenges posed by rare diseases. Although these registries encompass many patients with long periods of observation, there are nevertheless important drawbacks limiting their use: the inconsistency in the type of surgical intervention (subtotal versus total thyroidectomy; selective or systematic lymph node dissection versus none), pathological examination and ascertainment of outcomes (tumor recurrence versus persistence; cancer-specific survival versus overall 
survival), and the scarcity or imprecision of recorded information. The SEER database, for instance, is restricted to patients actively followed by SEER and excludes patients if they were dead based on autopsy or death certificate, or if they were not followed in a continuous fashion $(2,3)$. It does not distinguish between tumor extension into adjacent tissue (extrathyroidal growth) and lymph node metastases, both of which are subsumed under the umbrella term of 'regional' disease, nor does it record the cause of death, precluding the censoring of mortality unrelated to cancer. The SEER registry contains neither biochemical data (e.g. serum calcitonin) nor genetic data (e.g. germline mutations in the rearranged during transfection (RET) protooncogene), and does not provide information on the freedom of surgical margins from the tumor, or on recurrence and reoperations $(2,3)$. Moreover, extent of tumor and lymph node status is unknown for patients entered before 1998 (3). Most of the SEER data were contributed by general surgeons with limited expertise in endocrine surgery, let alone a rare pathologic entity such as medullary thyroid carcinoma, resulting in significant variability of practice patterns (3).

Special registries dedicated to individual cancers, such as the French medullary thyroid cancer registry (4), capture additional information unique to the cancer of interest (e.g. biochemical and genetic data, cause of death), without being able to overcome the lack of standardization among the contributing sites. Outside the setting of a multicenter clinical trial, only few highvolume surgical centers can supply the requisite homogeneity of surgical intervention (5). Such 'centers of excellence' frequently struggle to recruit sufficient numbers of medullary thyroid carcinoma patients within a reasonable period of time. In an effort to enlarge numbers, many specialist centers have resorted to pooling patients with medullary thyroid carcinoma spanning time periods as long as 20-40 years (5-8). Collapsing patients accrued over so many decades into one series creates an inhomogeneous study population that may not hold together sufficiently to evaluate timedependent outcomes ('time bias'). More advanced surgical techniques, such as compartment-oriented surgery using bipolar forceps coagulation and optical magnification $(9,10)$, have recently appeared on the scene, enabling more extensive neck operations with better histopathological mapping of locoregional tumor spread in more recent cohorts of patients. At the same time, more sophisticated imaging technologies (highresolution ultrasonography, computed tomography, magnetic resonance imaging and positron emission tomography) have refined the staging of tumors, giving rise to 'stage migration' over time (11).

This institutional study was designed to investigate time-dependent outcomes in a contemporaneous series of patients after initial neck surgery conducted between 1994 and 2002 for hitherto untreated medullary thyroid carcinoma, and to compare our recent outcomes with other series embracing several decades of recruitment.

\section{Patients and methods}

\section{Patient selection}

Between November 1994, the month when the concept of compartment-oriented surgery was implemented, and December 2002, a total of 128 consecutive patients were operated for hitherto untreated medullary thyroid carcinoma at this institution, a tertiary surgical center with referrals from all over Germany. December 2002 was chosen as a cut-off point to allow for a minimum observation period of 3 years. Patients referred for reoperation were not considered. Informed consent was obtained before each surgical procedure that represented standard practice of care in accordance with the practice guidelines of the German Society of Surgery (12). Because of the comparative longevity of many patients with medullary thyroid carcinoma in the face of advanced disease, distant metastases per se were not an exclusion criterion. Calcitonin levels were determined with the use of a solid two-site immunoradiometric calcitonin assay (ELSA-hCT, CIS Bio International, Gif-sur-Yvette, France). The upper normal limit of this assay is $<10 \mathrm{pg} / \mathrm{ml}$ (or $10 \mathrm{ng} / \mathrm{l}$ in Système International (SI) units), as verified in 83 normal volunteers aged $7-60$ years $(13,14)$. Normalization of serum calcitonin was assumed when this upper normal limit was not exceeded basally or on pentagastrin stimulation. Calcitonin stimulation was performed after obtaining informed consent through i.v. bolus injection of pentagastrin $(0.5 \mu \mathrm{g} / \mathrm{kg}$ body weight; Pentavlon, Laboratoires SERB, Paris, France); venous blood samples were drawn before the injection, and 2 and 5 min thereafter.

\section{Surgical intervention}

All surgical procedures were performed using optical magnification and bipolar coagulation, as described previously (15). All 128 consecutive patients underwent total thyroidectomy for hitherto untreated medullary thyroid carcinoma at this institution. In addition, 117 out of these 128 (91\%) patients underwent systematic dissection of the central lymph node compartment of the neck, which extends vertically from the hyoid bone to the thoracic inlet and horizontally between the carotid sheaths. The lateral lymph node compartments of the neck, which spread laterally from the carotid sheath to the trapezoid muscle and inferiorly from the subclavian vein to the hypoglossal nerve superiorly, were systematically dissected in 90 (70\%; ipsilateral) and 87 patients $(68 \%$; contralateral). The mediastinal lymph node compartment, which comprises all nodes between the 
brachiocephalic vein and tracheal bifurcation within the upper anterior and posterior mediastinum, was systematically dissected in 32 out of all $128(25 \%)$ consecutive patients. In the absence of formal lymph node dissection, freedom from lymph node metastasis was assumed in four nonindex RET carriers without lymph node dissection who normalized their abnormal pentagastrin-stimulated serum calcitonin levels after total thyroidectomy.

\section{Pathological examination and tumor staging}

A total of 128 entire thyroid glands were available for histopathological examination. After gross evaluation by the pathologist, the entire thyroid gland was divided vertically to separate the left and right lobes. The thyroid halves were then sectioned horizontally from the superior to the inferior pole, as described previously (16). After fixation in formalin, the whole thyroid gland was embedded in paraffin. Soft tissue and lymph nodes were processed separately. Conventional staining (hematoxylin and eosin) and calcitonin immunohistochemistry were performed on every surgical specimen, using the standard avidin-biotin complex peroxidase approach and a commercial polyclonal antibody (Immunotech, Marseilles, France). A diagnosis of medullary thyroid carcinoma was made in the presence of tumor extension beyond the basement membrane, demonstration of lymphatic or vascular invasion on histopathology, or a combination thereof. Primary tumor diameter was ascertained by direct measurements on the surgical thyroid specimens. While a diagnosis of lymph node metastasis usually required pathological confirmation, this need was waived for locoregional tumor recurrence and distant metastasis when there was such unequivocal evidence on ultrasonography, computerized tomography, magnetic resonance imaging, 18-fluorodeoxyglucose positron emission tomography, or a combination thereof.

\section{Clinicopathological variables and measurements of outcome}

Analyzed categorical variables included gender, heredity based on a positive DNA-based RET test, tumor extension beyond the thyroid capsule, presence of cervical and mediastinal lymph node metastases, evidence of distant metastasis at the time of initial neck operation, tracheal invasion, dissection of the central, lateral and mediastinal lymph node compartments, freedom of the surgical margins from the tumor on histopathology, and date and type of locoregional recurrence and death, whether related or unrelated to medullary thyroid carcinoma, calculated from the date of the initial thyroid operation. Continuous data were categorized as appropriate: age at first diagnosis in 20-year bands; primary tumor diameter in $20 \mathrm{~mm}$ bands; positive cervical and mediastinal lymph nodes in increments of 10; normal postoperative calcitonin levels with or without pentagastrin stimulation with a cut-off at the upper normal limit of the assay $(10 \mathrm{pg} / \mathrm{ml})$; and basal calcitonin levels at discharge with a cut-off at $250 \mathrm{mg} / \mathrm{ml}$, a proposed biochemical watershed of locoregional recurrence (17). Follow-up investigations were performed at the referring institutions according to local protocols mainly consisting of regular calcitonin measurements, computerized tomography, magnetic resonance imaging, and 18-fluorodeoxyglucose positron emission imaging. Locoregional recurrence and cause of death were ascertained using medical records, enquiries of physicians and hospitals involved in the care of each patient, death certificates, and autopsy findings. Locoregional events in patients with positive surgical margins at initial neck operation were interpreted as locoregional tumor persistence and not tumor recurrence.

\section{Statistical analysis}

Categorical and continuous data were tested on univariate analysis with the two-tailed Fisher's exact test and two-tailed exact Mann-Whitney-Wilcoxon rank sum test respectively. Multiple testing was adjusted for using the Bonferroni correction (18). For timeto-event analyses of outcome, the Kaplan-Meier method (19) was used in conjunction with the log-rank test (20). Time to event was calculated in months from the initial neck operation for medullary thyroid carcinoma until death or most recent follow-up, whichever came first. Unlike death, which is easily recognized, locoregional recurrence may have preceded its radiological or histopathological diagnosis for some time. Consequently, the Kaplan-Meier analysis systematically underestimates the actual rate of recurrent tumor growth, which remains unknown. Cancer-specific mortality was defined as death caused directly or indirectly by medullary thyroid carcinoma. Patients who died from unrelated causes were censored. The level of significance was set at $<0.05$.

\section{Results}

\section{Patient selection by availability of follow-up}

As shown in Table 1, the 120 patients with available follow-up after initial operation for medullary thyroid carcinoma did not significantly differ from their eight counterparts who were lost to follow-up. Despite disparities in absolute numbers, the two groups of patients appeared broadly comparable in all 15 clinicopathological variables examined (Table 1), allowing extrapolations of results from the 120 study patients with available follow-up to the whole institutional population of 128 patients.

Among the 120 patients with available follow-up, there were 63 RET carriers: 26 index patients (41\%) and 
Table 1 Patient selection by availability of follow-up.

\begin{tabular}{|c|c|c|c|}
\hline \multirow[b]{2}{*}{ Variable } & \multicolumn{2}{|c|}{ Follow-up $\boldsymbol{n}(\%)$} & \multirow[b]{2}{*}{$\boldsymbol{P}^{\mathrm{a}}$} \\
\hline & Available 120 (94) & Unavailable 8 (6) & \\
\hline Male gender, \% & 48 & 38 & 0.72 \\
\hline Age at first diagnosis, year, mean ( $95 \%$ confidence interval) & $40.3(36.4 ; 44.1)$ & $40.1(24.6 ; 55.7)$ & 0.99 \\
\hline Heredity (RET germline mutation), \% & 53 & 50 & $>0.99$ \\
\hline Primary tumor size, $\mathrm{mm}$, mean ( $95 \%$ confidence interval) & $16.3^{\mathrm{b}}(13.0 ; 19.7)$ & $17.6^{\mathrm{C}}(0 ; 37.2)$ & 0.86 \\
\hline Extrathyroidal extension, \% & 24 & 25 & $>0.99$ \\
\hline Lymph node metastasis, \% & 44 & 50 & $>0.99$ \\
\hline Distant metastasis at first diagnosis, $\%$ & 18 & 25 & 0.64 \\
\hline Tracheal invasion, \% & 7 & 0 & $>0.99$ \\
\hline Central lymph node dissection, \% & 92 & 88 & 0.49 \\
\hline Lateral lymph node dissection, ipsilateral, \% & 71 & 63 & 0.69 \\
\hline Lateral lymph node dissection, contralateral, \% & 68 & 63 & 0.71 \\
\hline Mediastinal lymph node dissection, \% & 25 & 25 & $>0.99$ \\
\hline Clear surgical margins (R0 resection), \% & 92 & 100 & $>0.99$ \\
\hline Normal postoperative basal calcitonin at discharge ( $<10 \mathrm{pg} / \mathrm{ml}), \%$ & 56 & $57^{\mathrm{C}}$ & $>0.99$ \\
\hline Postoperative basal calcitonin at discharge $>250 \mathrm{pg} / \mathrm{ml}$, \% & $25^{\mathrm{d}}$ & $29^{\mathrm{C}}$ & $>0.99$ \\
\hline
\end{tabular}

RET, rearranged during transfection protooncogene.

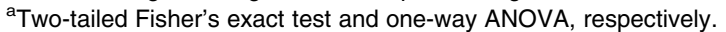

b Information missing for 6 patients, 5 of whom had extrathyroidal tumor growth

Information missing for 1 patient.

IInformation missing for 16 patients.

37 nonindex (59\%). These 63 RET carriers harbored missense mutations in codon 634 (28 patients; 44\%), codon 918 (11 patients; 17\%), codon 790 (9 patients; $14 \%$ ), codon 768 ( 4 patients; $6 \%$ ), codons 611 and 620 ( 3 patients or $5 \%$ each), codons 618 and 804 (2 patients or $3 \%$ each), and a 12 base pair duplication resulting in the insertion of four amino acids between codon 634 (Cys) and 635 (Arg; 1 patient; 2\%) as previously described (21). Our RET carriers generally have less advanced disease than our patients with sporadic medullary thyroid cancers, as reported elsewhere (15).

\section{Locoregional recurrence and cancer-specific death}

As detailed in Table 2, there were six locoregional recurrences in 110 patients with clear surgical margins diagnosed 8-94 months after initial neck resection, and five persistent locoregional tumors in ten patients with involved surgical margins detected 2-13 months after initial neck resection. Four of the six locoregional recurrences were confirmed on histopathological examination: one patient had a tumor infiltrate in the central neck; one patient revealed a positive lateral lymph node; and two patients each harbored tumor infiltrates in the lateral neck in conjunction with lateral cervical or nuchal lymph node metastases.

Altogether, there were 19 deaths, 12 of which (63\%) were attributed to recurrent or persistent medullary thyroid carcinoma (Table 2): among these 12 patients, four patients had lung metastases, one patient had liver metastases, and one patient a combination of lung and bone metastases. Of the five patients with lung metastases, two patients developed (presumably retention) pneumonia, and one patient pulmonary failure, progressive disease and pneumothorax each. Two cancer-specific deaths coincided with locoregional recurrences, and three additional cancer-specific deaths occurred in conjunction with locoregional tumor persistence. No locoregional tumor recurrence or persistence was seen in seven further cancer-specific deaths. The remaining seven deaths $(37 \%)$ were unrelated to medullary thyroid cancer: lymphoplasmocytic immunocytoma at 46 years; pulmonary embolism secondary to urinary bladder carcinoma at 77 years; peritonitis following perforation of a sigmoid diverticulum at 58 years; septicemia due to hemorrhagic pneumonia diagnosed on postmortem at 33 years; blunt trauma in a high-speed motor vehicle accident at 13 years; left ventricular failure at 78 years and 'old age' at 74 years.

\section{Recurrence-free survival}

On Kaplan-Meier analysis of the 110 patients with clear surgical margins at initial neck operation, most examined variables were significantly associated with recurrence-free survival after Bonferroni correction for multiple testing (Table 3): primary tumor diameter grouped in $20 \mathrm{~mm}$ bands, extrathyroidal tumor growth, number of cervical and mediastinal lymph node metastases, frequency of distant metastasis, tracheal invasion, postoperative basal calcitonin levels > $250 \mathrm{pg} / \mathrm{ml}$, and persistent hypercalcitoninemia (all $P \leq 0.005$; log-rank test). Only nominally significant $(P=0.042)$ were sporadic tumors, and nonsignificant were male gender and age classed in 20-year bands. Patients with node-negative medullary thyroid carcinomas and those with normalization of basal serum calcitonin levels at discharge did not develop 
Table 2 Locoregional recurrence and cancer-specific death.

\begin{tabular}{|c|c|c|c|c|c|}
\hline $\begin{array}{l}\text { Age at first } \\
\text { diagnosis, years }\end{array}$ & $\begin{array}{l}\text { Surgical } \\
\text { margins }\end{array}$ & $\begin{array}{l}\text { Time to locoregional } \\
\text { recurrence, months }\end{array}$ & $\begin{array}{l}\text { Confirmation of } \\
\text { locoregional recur- } \\
\text { rence/persistence }\end{array}$ & $\begin{array}{l}\text { Time to cancer- } \\
\text { specific death, } \\
\text { months }\end{array}$ & Cause of cancer-specific death \\
\hline 56 & Clear & 8 & Histopathology ${ }^{a}$ & & \\
\hline 30 & Clear & 13 & Histopathology ${ }^{b}$ & & \\
\hline 75 & Clear & 25 & Histopathology ${ }^{\mathrm{C}}$ & & \\
\hline 69 & Clear & 26 & Tracheal obstruction & 26 & $\begin{array}{l}\text { Tracheal obstruction, S/P stent } \\
\text { placement }\end{array}$ \\
\hline 43 & Clear & 30 & Unspecified & 30 & $\begin{array}{l}\text { 'Thyroid cancer' as per death } \\
\text { certificate }\end{array}$ \\
\hline 20 & Clear & 94 & Histopathology $^{d}$ & & \\
\hline 70 & Involved & 2 & Unspecified & 2 & $\begin{array}{l}\text { 'Foreign body respiratory tree' as } \\
\text { per death certificate }\end{array}$ \\
\hline 64 & Involved & 6 & Unspecified & 16 & $\begin{array}{l}\text { Malignant pleural effusion, } \\
\text { pneumonia }\end{array}$ \\
\hline 31 & Involved & 8 & Unspecified & 9 & Pneumothorax, lung metastases \\
\hline 10 & Involved & 12 & Cervical ultrasound & & \\
\hline 70 & Involved & 13 & Cervical ultrasound & & \\
\hline 12 & Clear & & & 6 & $\begin{array}{l}\text { Septicemia from pneumonia due } \\
\text { to lung metastasis }\end{array}$ \\
\hline 63 & Clear & & & 14 & $\begin{array}{l}\text { Pneumonia due to lung } \\
\text { metastases }\end{array}$ \\
\hline 69 & Clear & & & 16 & $\begin{array}{l}\text { 'Thyroid cancer' as per death } \\
\text { certificate }\end{array}$ \\
\hline 68 & Clear & & & 23 & $\begin{array}{l}\text { Progressive disease, lung and } \\
\text { bone metastases }\end{array}$ \\
\hline 61 & Clear & & & 50 & $\begin{array}{l}\text { Progressive disease, liver } \\
\text { metastases }\end{array}$ \\
\hline 45 & Involved & & & 36 & $\begin{array}{l}\text { Pulmonary failure due to lung } \\
\text { metastases }\end{array}$ \\
\hline 9 & Involved & & & 38 & Progressive disease \\
\hline
\end{tabular}

$\mathrm{S} / \mathrm{P}$, status post.

$\mathrm{a}_{1}$ of 2 lateral cervical lymph nodes involved, 1 lateral cervical infiltrate.

${ }^{b} 1$ of 1 lateral cervical lymph node involved.

${ }^{\mathrm{c}} 2$ of 2 nuchal lymph nodes involved and 1 nuchal infiltrate.

$\mathrm{d}_{1}$ central cervical infiltrate.

locoregional recurrences during the median observation period of 64.5 months. The rarity of locoregional recurrence (only six events among 110 eligible patients) did not permit us to conduct multivariate analyses. Altogether, the median 5-year recurrence-free survival was $95.2 \%$ (Fig. 1a), with a corresponding median recurrence rate of $4.8 \%$ and a median time interval to diagnosis of locoregional recurrence of 25.5 months (range 8-94 months) since the initial neck operation.

\section{Cancer-specific survival}

Cancer-specific survival was $89.3 \%$ at 5 years, with a corresponding median cancer-specific mortality of $10.7 \%$ and a median time interval to cancer-specific death of 19.5 months (range 2-50 months) since the initial neck operation. As shown in Fig. 1b, no cancerspecific mortality was seen after more than 50 months of observation. Except for gender (nonsignificant), age at first diagnosis greater than 60 years and sporadic tumors (both only nominally significant), all other variables tested were significantly $(P<0.001$; log-rank test) associated with cancer-specific survival after Bonferroni correction for multiple testing (Table 4).
Many of these significant variables were obviously interrelated: primary tumor diameter, extrathyroidal growth, number of lymph node metastases, frequency of distant metastasis, tracheal invasion, freedom of the surgical margins from the tumor, postoperative rates of calcitonin normalization, and residual calcitonin levels after surgical intervention. The number of events (12 cancer-specific deaths among 120 patients) during the median observation period of 64.5 months was not large enough to incorporate all clinicopathological variables into a single multivariate model.

\section{Discussion}

The present study differs from earlier investigations with respect to the homogeneity of the patient group for initial therapy. It is the first contemporaneous singleinstitution series encompassing more than 100 patients, accrued within less than a decade, who underwent extensive cervical resection for hitherto untreated medullary thyroid carcinoma. Our comparatively brief recruiting period of 8.2 years for 120 patients was far shorter than the lengthy recruitment 
Table 3 Recurrence-free survival in 110 consecutive medullary thyroid cancer patients with clear surgical margins and follow-up (KaplanMeier analysis).

\begin{tabular}{|c|c|c|c|c|c|}
\hline Variable & Category & Patients $n$ & Events $n$ & $\begin{array}{c}\text { Recurrence-free } \\
\text { survival, months, } \\
\text { median (range) }\end{array}$ & $P$ log-rank \\
\hline Gender & $\begin{array}{l}\text { Female } \\
\text { Male }\end{array}$ & $\begin{array}{l}58 \\
52\end{array}$ & 3 & $65(5-35)$ & 0.92 \\
\hline \multirow[t]{4}{*}{ Age at first diagnosis } & $\leq 20$ years & 22 & 1 & $72.7(6-135)$ & $0.18^{\mathrm{a}}$ \\
\hline & $21-40$ years & 32 & 1 & $69.5(11-115)$ & \\
\hline & $41-60$ years & 35 & 2 & $65(8-111)$ & \\
\hline & $>60$ years & 21 & 2 & $46(5-109)$ & \\
\hline \multirow[t]{2}{*}{ Tumor entity } & Hereditary & 59 & 1 & $72(6-135)$ & 0.042 \\
\hline & Sporadic & 51 & 5 & $50(5-111)$ & \\
\hline \multirow[t]{3}{*}{ Primary tumor diameter ${ }^{b, c}$} & $\leq 20 \mathrm{~mm}$ & 85 & 2 & $69(5-135)$ & $0.005^{a, d}$ \\
\hline & $20.1-40 \mathrm{~mm}$ & 11 & 2 & $45(8-108)$ & \\
\hline & $40.1-60 \mathrm{~mm}$ & 9 & 2 & $79(6-100)$ & \\
\hline \multirow[t]{2}{*}{ Tumor growth } & Intrathyroidal & 91 & 2 & $70(5-135)$ & $<0.001^{d}$ \\
\hline & Extrathyroidal & 19 & 4 & $45(6-85)$ & \\
\hline \multirow[t]{3}{*}{ Lymph nodes involved } & 0 & $67^{\mathrm{e}}$ & 0 & $76(5-135)$ & $<0.001^{\mathrm{a}, \mathrm{d}}$ \\
\hline & $1-10$ & 23 & 2 & $65(11-108)$ & \\
\hline & $>10$ & 20 & 4 & $39.5(6-85)$ & \\
\hline \multirow{2}{*}{ Distant metastasis at first diagnosis } & Unconfirmed & 95 & 3 & $70(5-135)$ & $<0.001^{\mathrm{d}}$ \\
\hline & Confirmed & 15 & 3 & $41(6-84)$ & \\
\hline \multirow[t]{2}{*}{ Tracheal invasion } & Absent & 107 & 3 & $68(5-135)$ & $<0.001^{d}$ \\
\hline & Present & 3 & 3 & $26(25-30)$ & \\
\hline \multirow{2}{*}{$\begin{array}{l}\text { Postoperative basal calcitonin at } \\
\text { discharge }\end{array}$} & Normal & 66 & 0 & $74.5(5-135)$ & $<0.001^{d}$ \\
\hline & Increased & 44 & 6 & $45.5(6-108)$ & \\
\hline \multirow{2}{*}{$\begin{array}{l}\text { Postoperative basal calcitonin at } \\
\text { discharge }^{f}\end{array}$} & $\leq 250 \mathrm{pg} / \mathrm{ml}$ & 77 & 2 & $73(5-113)$ & $<0.001^{d}$ \\
\hline & $>250 \mathrm{pg} / \mathrm{ml}$ & 20 & 4 & $43(6-84)$ & \\
\hline
\end{tabular}

${ }^{\mathrm{a} C}$ Comparing the two groups at the extremes of the spectrum.

bInformation missing for 3 patients, 2 of whom had extrathyroidal tumor growth

${ }^{\mathrm{c}}$ Excluding 2 patients without recurrences who had primary tumors $>60 \mathrm{~mm}$.

dSignificant after Bonferroni correction for multiple testing.

e Including 4 nonindex RET carriers without lymph node dissection who normalized their abnormal calcitonin levels after total thyroidectomy.

IInformation missing for 13 patients.

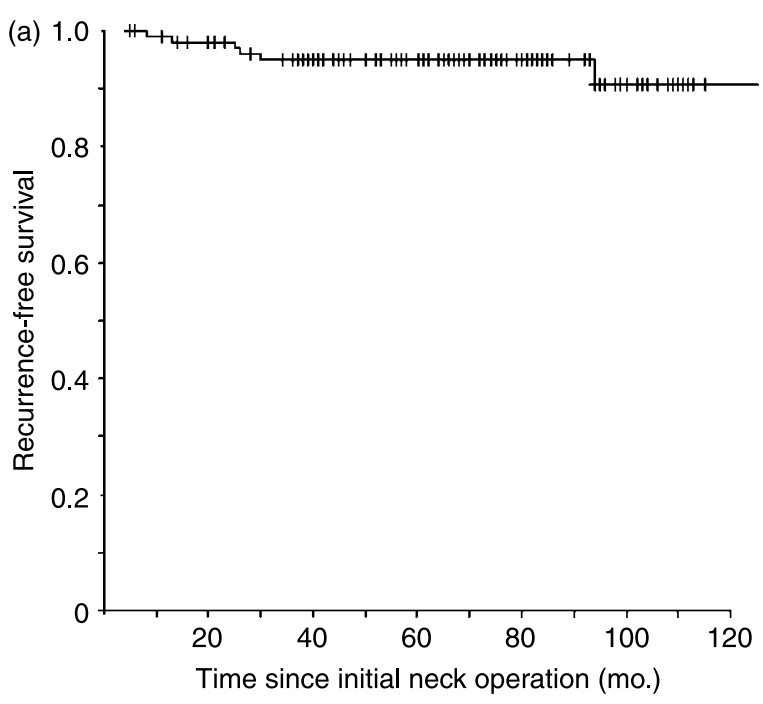

Patients at risks, $n$ :

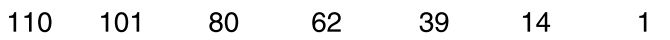

Figure 1 Recurrence-free and cancer-specific survival.

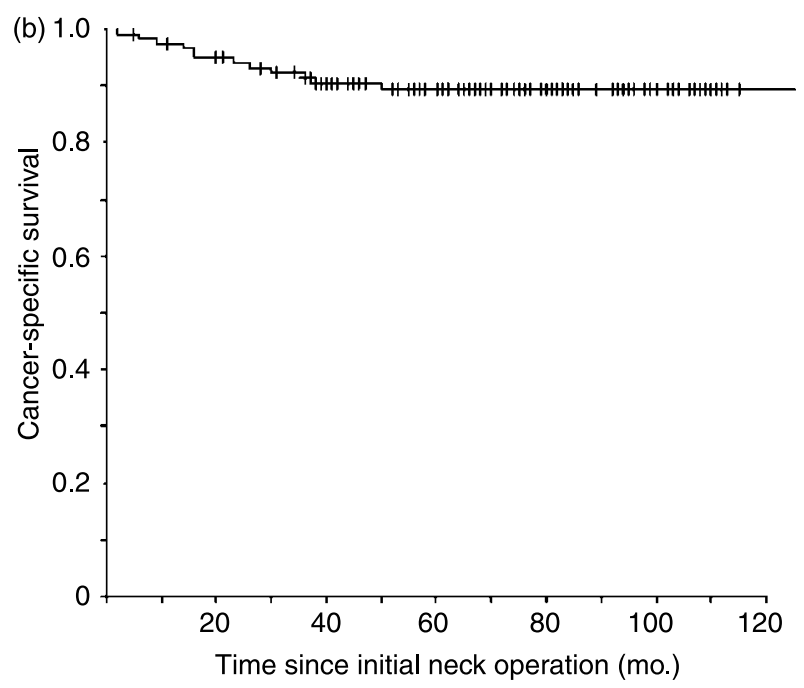

Patients at risks, $n$ :

$\begin{array}{lllllll}120 & 110 & 85 & 64 & 39 & 15 & 1\end{array}$


Table 4 Cancer-specific survival in 120 consecutive medullary thyroid carcinoma patients with follow-up (Kaplan-Meier analysis).

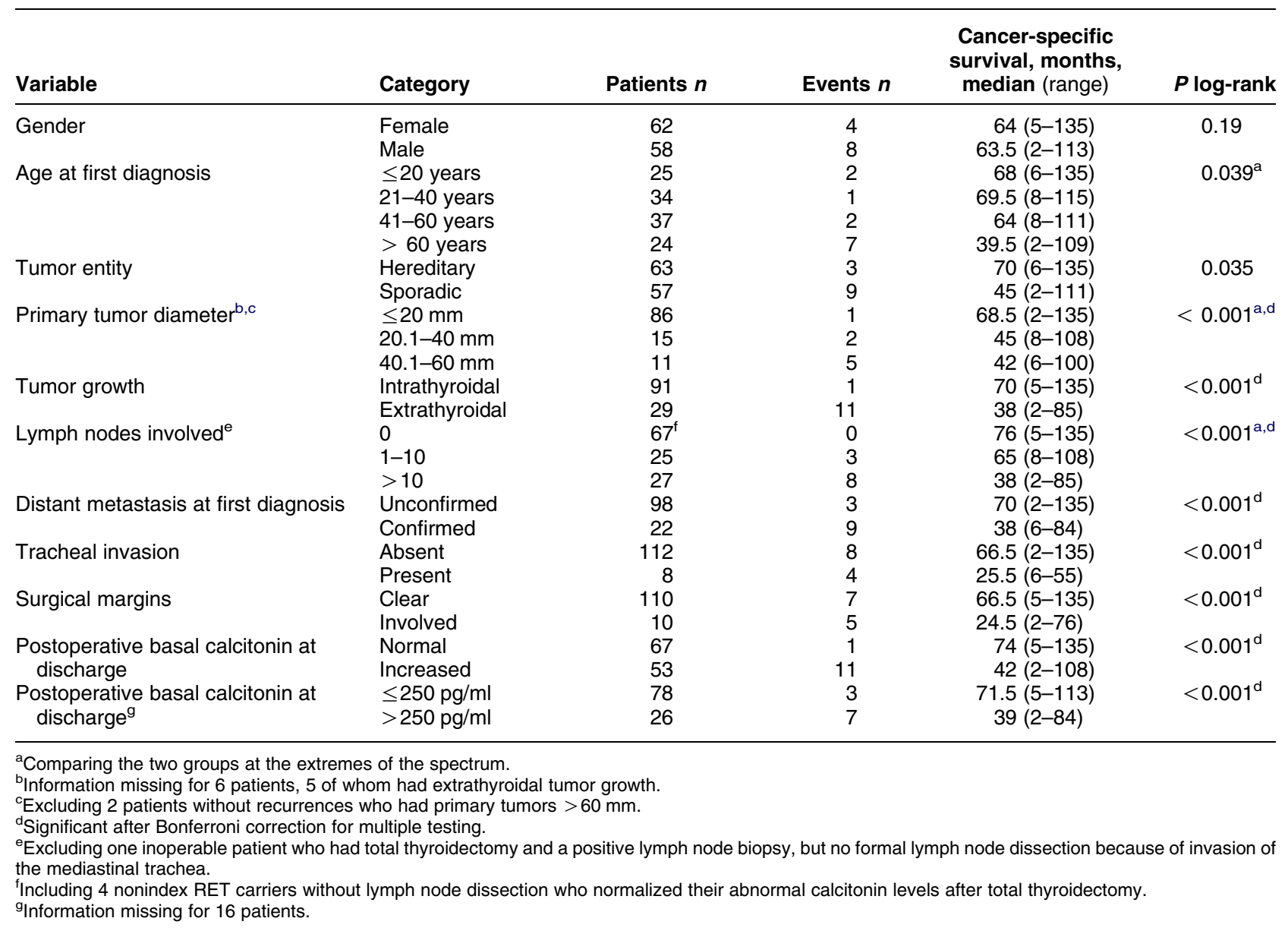

periods reported in other institutional series of 23 years for 53 patients (7), 34 years for 120 patients (8), and 39 years for 73 (6) and 104 patients (5). Compared with other institutional series (5-8), our patients tended to be younger (mean of 40 versus 43-46 years), to harbor RET germline mutations more often (53 vs $17-45 \%$ ), and to have node-positive medullary thyroid carcinomas less frequently (44 vs $47-74 \%$ ), perhaps owing to more comprehensive biochemical (22) and DNAbased screening (23). Because the proportion of RET carriers in our study population exceeded the rate of patients with familial cancers seen at other specialist centers $(4,5,8)$, more selective referral of younger RET carriers with localized disease to our institution may represent an alternative explanation for these findings. Our patients also underwent systematic lymph node dissections more often (92 vs 43-78\%), possibly owing to intervening advances in surgical technology. Our patients were comparable with other literature series with regard to gender (female; 52 vs 50-57\%), extrathyroidal extension (24 vs $28 \%$ ), distant metastasis (18 vs $7-23 \%$ ), and total thyroidectomy (100 vs $98 \%$ ). Although our data are recent, our median followup period of 5.4 years (64.5 months) compared favorably with other series with median observation periods of 3 and 5 years $(4,5)$, but was appreciably shorter than the median follow-up period of 8 years in de Groot's study (8).

\section{Time to diagnosis of locoregional recurrence}

Time to locoregional recurrence after extensive cervical resection has not been studied in great detail, possibly because of the need for more extensive resection and histopathological analysis to distinguish locoregional tumor recurrence based on clear surgical margins from locoregional tumor persistence. Using comparable criteria for locoregional recurrence, de Groot et al. (8) reached a $50 \%$ recurrence rate (60 events among 120 patients) during a median follow-up of 8 years. With our extensive surgical approach, however, the locoregional recurrence rate was just $4.8 \%$ at 5 years and $5.4 \%$ overall (six events among 110 eligible patients). Although it cannot be ruled out that some slow-growing recurrent locoregional tumors may have evaded identification by postoperative imaging during our shorter median observation period of 64.5 months ( 5.4 years) only to emerge later on, our recurrence rates might have 
been higher with a surgical approach less extensive than ours. Considering our four patients with histopathologically confirmed locoregional recurrence, tumor infiltrates and lymph node metastases clearly favored the lateral neck (Table 2). In hindsight, these data indicated that the initial compartment-oriented lymph node dissection may have been adequate in the thyroid bed and central neck, but should have been carried more into the lateral neck.

\section{Time to cancer-specific death}

Compared with other published series with a high proportion of familial cancers, our cancer-specific mortality rate of $10.7 \%$ at 5 years was at the lower end, equaling the $10.7 \%$ rate of Kebebew et al. (5) and surpassing the $14.3 \%$ rate of Modigliani et al. (4). These data may cause one to think that more extensive surgical intervention in the neck may be unable to further substantially improve cancer-specific survival rates among contemporaneous patients, many of whom harbor localized medullary thyroid cancers. As a matter of principle, the extent of surgical intervention was not reduced in this series just because of age and hence is at variance with other studies that limited the scope of neck resection for elderly patients (2). In keeping with our data, age at diagnosis was also nonsignificant in de Groot's study (8) who adjusted disease-specific survival for the baseline mortality rate in the general population.

\section{Clinical implications}

In comparison with literature data, our patients showed evidence of more localized tumors at younger ages; a relative increase of hereditary tumors that, owing to DNA-based analysis, are no longer misclassified as sporadic; and a decrease in node-positive medullary thyroid carcinomas despite more extensive lymph node dissection and more accurate ascertainment. The growing proportion of localized medullary thyroid carcinomas among contemporaneous patients can be expected to ultimately lower the event rates, complicating future studies of outcome.

\section{Acknowledgements}

We are indebted to the physicians and institutions involved in the post-operative care of our patients for providing valuable follow-up information.

\section{References}

1 Bergholm U, Adami HO, Telenius-Berg M, Johansson H \& Wilander E. Incidence of sporadic and familial medullary thyroid carcinoma in Sweden 1959 through 1981. A nationwide study in 126 patients. Swedish MCT Study Group. Acta Oncologica 199029 9-15.
2 Gilliland FD, Hunt WC, Morris DM \& Key CR. Prognostic factors for thyroid carcinoma. A population-based study of 15,698 cases from the Surveillance, Epidemiology and End Results (SEER) Program 1973-1991. Cancer 199779 564-573.

3 Roman S, Lin R \& Sosa JA. Prognosis of medullary thyroid carcinoma: demographic, clinical, and pathologic predictors of survival in 1252 cases. Cancer 2006107 2134-2142.

4 Modigliani E, Cohen R, Campos JM, Conte-Devolx B, Maes B, Boneu A, Schlumberger M, Bigorgne JC, Dumontier P, Leclerc L, Corcuff B, Guilhem I \& the GETC Study Group. Prognostic factors for survival and for biochemical cure in medullary thyroid carcinoma: results in 899 patients. Clinical Endocrinology 1998 48 265-273.

5 Kebebew E, Ituarte PHG, Siperstein AE, Duh QY \& Clark OH. Medullary thyroid carcinoma: clinical characteristics, treatment, prognostic factors, and a comparison of staging systems. Cancer 200088 1139-1148.

6 Brierley J, Tsang R, Simpson WJ, Gospodarowicz M, Sutcliffe S \& Panzarella T. Medullary thyroid cancer: analyses of survival and prognostic factors and the role of radiation therapy in local control. Thyroid 19966 305-310.

7 Dottorini ME, Assi A, Sironi M, Sangalli G, Spreafico G \& Colombo L. Multivariate analysis of patients with medullary thyroid carcinoma. Prognostic significance and impact on treatment of clinical and prognostic variables. Cancer 199677 $1556-1565$.

8 de Groot JWB, Plukker JTM, Wolffenbuttel BHR, Wiggers T, Sluiter WJ \& Links TP. Determinants of life expectancy in medullary thyroid cancer: age does not matter. Clinical Endocrinology $2006 \mathbf{6 5} 729-736$.

9 Tisell LE, Hansson G, Jansson S \& Salander H. Reoperation in the treatment of asymptomatic metastasizing medullary thyroid carcinoma. Surgery 198699 60-66.

10 Dralle H, Damm I, Scheumann GFW, Kotzerke J, Kupsch E, Geerlings H \& Pichlmayr R. Compartment-oriented microdissection of regional lymph nodes in medullary thyroid carcinoma. Surgery Today 199424 112-121.

11 Feinstein AR, Sosin DM \& Wells CK. The Will Rogers phenomenon. Stage migration and new diagnostic techniques as a source of misleading statistics for survival in cancer. New England Journal of Medicine 1985312 1604-1608.

12 Röher HD, Simon D \& Goretzki PE. Guidelines in oncologic surgery: malignant thyroid tumors. Langenbeck's Archives of Surgery 1997114 (suppl) 142.

13 Guilloteau D, Perdrisot R, Calmettes C, Baulieu JL, Lecomte P, Kaphan G, Milhaud G, Besnard JC, Jallet P \& Bigorgne JC. Diagnosis of medullary carcinoma of the thyroid (MCT) by calcitonin assay using monoclonal antibodies: criteria for the pentagastrin stimulated test in hereditary MCT. Journal of Clinical Endocrinology and Metabolism 199071 1064-1067.

14 Perdrisot R, Bigorgne JC, Guilloteau D \& Jallet P. Monoclonal immunoradiometric assay of calcitonin improves investigation of familial medullary thyroid carcinoma. Clinical Chemistry 199036 381-383.

15 Machens A, Hinze R, Thomusch O \& Dralle H. Pattern of nodal metastasis for primary and reoperative thyroid cancer. World Journal of Surgery 200226 22-28.

16 Hinze R, Holzhausen HJ, Gimm O, Dralle H \& Rath FW. Primary hereditary medullary thyroid carcinoma - C-cell morphology and correlation with preoperative calcitonin levels. Virchows Archives 1998433 203-208.

17 Yen TWF, Shapiro SE, Gagel RF, Sherman SI, Lee JE \& Evans DB. Medullary thyroid carcinoma: results of a standardized surgical approach in a contemporary series of 80 consecutive patients. Surgery 2003134 890-901.

18 Bland JM \& Altman DG. Multiple significance tests: the Bonferroni method. British Medical Journal 1995310170.

19 Kaplan EL \& Meier P. Nonparametric estimation from incomplete observations. Journal of the American Statistical Association 1958 53 457-481. 
20 Peto R, Pike MC, Armitage P, Breslow NE, Cox DR, Howard SV, Mantel N, McPherson K, Peto J \& Smith PG. Design and analysis of randomized clinical trials requiring prolonged observation of each patient. II. Analysis and examples. British Journal of Cancer 1977 $351-39$.

21 Höppner W \& Ritter MM. A duplication of $12 \mathrm{bp}$ in the critical cysteine rich domain of the RET proto-oncogene results in a distinct phenotype of multiple endocrine neoplasia type $2 \mathrm{~A}$. Human Molecular Genetics 19976 587-590.

22 Elisei R, Bottici V, Luchetti F, Di Coscio G, Romei C, Grasso L, Miccoli P, Iacconi P, Basolo F, Pinchera A \& Pacini F. Impact of routine measurement of serum calcitonin on the diagnosis and outcome of medullary thyroid cancer: experience in 10,864 patients with nodular thyroid disorders. Journal of Clinical Endocrinology and Metabolism 200489 163-168.

23 Lips CJM, Landsvater RM, Höppener JWM, Geerdink RA, Blijham G, Jansen-Schillhorn van Veen JM, van Gils APG, De Wit MJ, Zewald RA, Berends MJH, Beemer FA, BrouwersSmalbraak J, Jansen RPM, Ploos van Amstel HK, van Vroonhoven TJMV \& Vroom TM. Clinical screening as compared with DNA analysis in families with multiple endocrine neoplasia type 2A. New England Journal of Medicine 1994331 828-835.

Received 13 February 2007

Accepted 19 April 2007 